\title{
Fotografia de crianças e seus personagens midiáticos: contribuições para pensarmos as práticas educomunicativas no contexto educacional contemporâneo*
}

\author{
Ademilde Silveira Sartori \\ Doutora em Comunicação pela USP, professora do Programa de Pós-Graduação em Educação - \\ PPGE/UDESC.
}

E-mail: ademildesartori@gmail.com

Patrícia Justo Moreira

Doutoranda em Educação - PPGE/UDESC.

E-mail: patriciajusto.moreira@gmail.com

Kamila Regina de Souza

Mestre em Educação - PPGE/UDESC.

E-mail: kamila.brasil@hotmail.com

Resumo: O presente artigo expõe reflexões sobre a presença de personagens midiáticos na cultura infantil por meio da análise de seis fotografias de diferentes épocas de acervos de família que trazem crianças vestidas com fantasias dos seus personagens midiáticos preferidos. Uma vez que as referências midiáticas vêm desafiando a escola a lidar com um mundo de informações que ultrapassam seus muros, o contato com os acervos fotográficos de família revelaram possibilidades para se pensar no desenvolvimento de práticas pedagógicas educomunicativas.

Palavras-chave: fotografia; personagens midiáticos; práticas pedagógicas educomunicativas.
Abstract: This paper presents discussions on the presence of media characters on children's culture through the analysis of six photographs from different periods of family collections in which the children are dressed in costumes of their favorite media characters. Once the media references have been challenging the school in the process of dealing with the information beyond its walls, the contact with family photographs collections points to the possibility to think in the development of educommunicative pedagogical practices.

Keywords: photography; media characters; educommunicative pedagogical practices.
Recebido em: 28/02/2013

Aprovado em: 16/05/2013

* Trabalho apresentado no GP Comunicação e Educação, do XII Encontro dos Grupos de Pesquisa em Comunicação, evento componente do XXXV Congresso Brasileiro de Ciências da Comunicação, com atualizações para publicação. 
comunicação \& educação • Ano XVIII • número 2 • jul/dez 2013

\section{AS CRIANÇAS E OS PERSONAGENS MIDIÁTICOS}

[...] A TV, como os videojogos e, em certa medida, os computadores favorecem um novo tipo de compreensão e de comunicação baseada nas propriedades da imagem [...].

Elza Dias Pacheco

Ao interagir com as imagens, com as mídias e com pessoas de diferentes idades e realidades e assim vivenciar as mais variadas experiências sociais e culturais, as crianças constroem seus conhecimentos e valores próprios. De acordo com Salgado, Pereira e Jobim e Souza1, "atribuir sentidos às imagens buscando nelas ou atribuindo a elas uma história é também cultivar a possibilidade de contar nossa própria história, recuperando a narrativa e a atenção, sem abdicar da nossa relação com as imagens - signos da cultura contemporânea”. Dessa forma, as referências às quais o sujeito contemporâneo tem acesso atuam na sua constituição, na sua forma de ver, sentir e agir no mundo.

Ao observarmos a produção cultural destinada ao público infantil, percebemos que as narrativas reúnem elementos como imagem, som, movimento, fala, escrita, enfim, linguagens que possibilitam que as crianças se identifiquem com as histórias e os personagens que apresentam. Citelli ${ }^{2}$ chama de linguagem complexa esse encontro de diferentes signos num mesmo campo de representação.

Benjamim $^{3}$ afirma que as transformações na percepção sensorial e cognitiva humana que surgiram com o desenvolvimento dos media fazem com que as pessoas desenvolvam novas sensibilidades na sua representação de mundo. Compreende-se que esse novo sensorium é desenvolvido cada vez mais cedo pelas pessoas, que desde crianças entram em contato com diversas linguagens e produtos audiovisuais e os integram à sua cultura pessoal.

A brincadeira dá às crianças a chance de criar e recriar inúmeras situações aliando a imaginação e os inúmeros outros elementos com os quais ela interage em seu dia a dia. Ao observarmos as falas das crianças, percebemos elementos que evidenciam o quanto elas constroem seus conhecimentos e perspectivas sociais e culturais a partir do universo da produção cultural para as crianças. Para Barbosa ${ }^{4}$, o fato é que:

[...] As crianças se misturam, assimilam e produzem culturas que provêm da socialização tanto da cultura dos videogames, das princesas, das redes, dos CDs, como também da cultura dos amigos, do futebol, dos laços de afeto, da vida em grupo na escola e na família, tudo em um mesmo espaço e tempo social e pessoal [...].

JOBIM; SOUZA, 2005, p. 13

2. CITELLI, 2004, p. 23.

3. BENJAMIM, 1992, p. 80.

4. BARBOSA, 2007, p. 1069.
Entendendo a fotografia como uma representação que não é neutra, uma vez que o universo das representações está diretamente ligado à cultura, este artigo se propõe a refletir sobre a presença dos personagens midiáticos na vida das crianças por meio da análise de seis fotografias, obtidas de acervos 
de família e de diferentes épocas, que retratam crianças fantasiadas de seus personagens preferidos. As fotografias foram cedidas por pessoas que fazem parte de nosso quadro de referência pessoal e que souberam de nosso interesse de pesquisa. Todas as fotografias, bem como os relatos descritivos das mesmas, foram utilizados com autorização por escrito das pessoas fotografadas e/ou de seus pais ou responsáveis. As crianças e as famílias são identificadas por letras para garantir o anonimato.

O intuito deste artigo é apresentar a análise das fotografias por meio da articulação da leitura dessas imagens e dos relatos dos familiares e/ou dos próprios fotografados, com a intenção de promover interpretações que ampliem a compreensão sobre a forma com a qual as crianças se relacionam com os personagens midiáticos nos contextos familiares contemporâneos e como isso pode ensejar práticas pedagógicas educomunicativas.

\title{
2. AS CRIANÇAS E SEUS PERSONAGENS MIDIÁTICOS: FOTOGRAFIAS E SEUS RELATOS
}

\author{
"Agora eu era o herói/ \\ e o meu cavalo só falava inglês." \\ Chico Buarque/Sivuca
}

A seguir serão apresentadas as contextualizações das narrativas dos personagens com os quais as crianças fotografadas estão caracterizadas, os relatos das pessoas fotografadas ou dos seus familiares e as análises das fotografias. Não pretendemos, no entanto, realizar um estudo aprofundado quanto aos personagens midiáticos em si, tampouco sobre as questões que dizem respeito ao campo da fotografia, mas um reconhecimento de que seria necessário recorrer a uma busca por informações sobre os personagens de modo a facilitar o entendimento da relação das crianças com os mesmos, com vistas a pensar proposições para uma prática pedagógica educomunicativa. As fotografias disponibilizadas para o presente estudo mostram crianças vestidas respectivamente com fantasias dos seguintes personagens midiáticos: "Jeannie é um Gênio", "Jaspion", "Homem-Aranha", "Harry Potter", "Batman" e "Batgirl".

O seriado "Jeannie é um Gênio"s fez grande sucesso no Brasil, sendo exibido primeiramente na década de 1960 pela TV Paulista, que na época fazia parte da Rede Globo e, nas décadas seguintes, foi reprisada em várias emissoras brasileiras.

De acordo com o relato da própria "A", fotografada enquanto ainda era uma menina, a fotografia foi feita no Carnaval de 1981 em Santos/SP, cidade onde morava: "Eu estava vindo de uma matinê... é só olhar como eu estava descabelada", diz rindo. Ela afirma ainda que adorava o seriado "Jeannie é um Gênio", o qual contava a história de um astronauta americano que conhece uma feiticeira, se apaixona e se casa com ela.

5. Informações disponíveis em: <http://pt.wikipedia. org/wiki/l_Dream_of_ Jeannie>. Acesso em: mar. 2013 


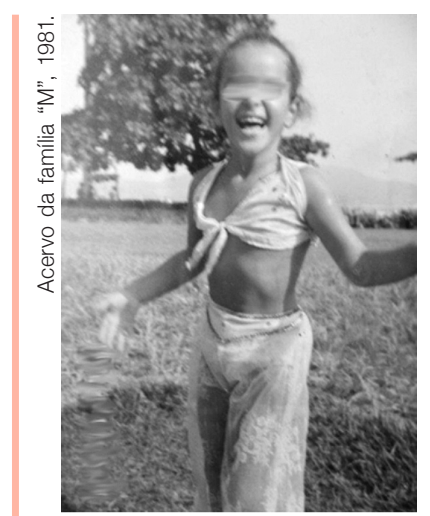

"A" (“Jeannie é um Gênio").

Percebe-se que "A" foi fotografada num espaço amplo e aberto, e não em um estúdio fotográfico, como era comum naquela época. Outro aspecto que se pode destacar nesta fotografia é o fato de que, embora expresse um largo sorriso, "A" não faz pose, assim ela parece muito à vontade com a situação.

Já a fotografia abaixo - na qual "B" veste-se de Jaspion - foi feita num estúdio fotográfico e, embora o menino sorria, ele não olha em direção à câmera. É possível perceber também que a parede de fundo do estúdio está coberta por um papel de parede com motivos de paisagem, o que remete a certa neutralidade. A mãe de "B" relata que a fotografia foi feita no ano de 1989, quando o menino tinha quatro anos de idade, num estúdio fotográfico localizado no município de São José/SC, cidade onde moram até hoje. A opção pelo estúdio foi em função de a família não ter condições financeiras para adquirir uma câmera fotográfica na época.

De acordo com a mãe de "B", ele gostava muito do personagem Jaspion, por isso quis ser fotografado fantasiado: "Ele assistia todos os dias ao seriado na televisão e imitava o personagem, só tirava a fantasia para dormir e tomar banho. Ele usou a fantasia até rasgar!". Ela conta que a fantasia foi comprada no Mercado Público de Florianópolis/SC e que a roupa vinha acompanhada de máscara e espada. A mãe relata ainda que ele brincava com a espada quando usava a fantasia, mas ela, como não gostava da brincadeira, escondia a espada dele. Ela finaliza seu relato explicando que nesta fotografia ele não está com a fantasia completa, mas que tinha outra fotografia em que ele estava também com a máscara, porém, esta foi rasgada acidentalmente por um dos seus netos, filho de "B".

A série "Jaspion" foi transmitida no Brasil inicialmente pela Rede Manchete a partir de 1988 e posteriormente passou a ser exibida por outras emissoras, mantendo sempre elevados índices de audiência. O seriado narra as aventuras do super-herói Jaspion, que foi encontrado ainda criança pelo profeta Edim após um acidente espacial em que seus pais morreram. Jaspion cresce convivendo com animais e com a vida selvagem e, quando adulto, é alertado por Edim da ameaça de Satan Goss sobre o universo, ameaça essa prevista na bíblia galáctica. Para livrar-se de Satan Goss, Jaspion parte pelo espaço até chegar à Terra. A do gênero de super-heróis japoneses e se tornou muito popular.

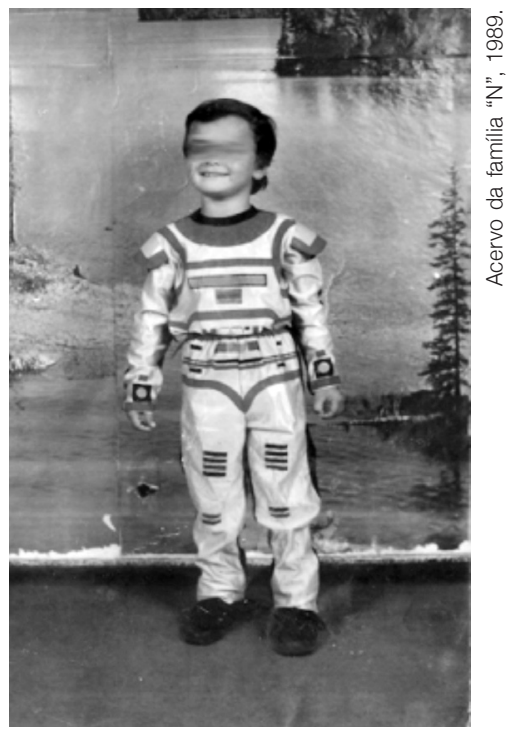

"B" (“Jaspion") 


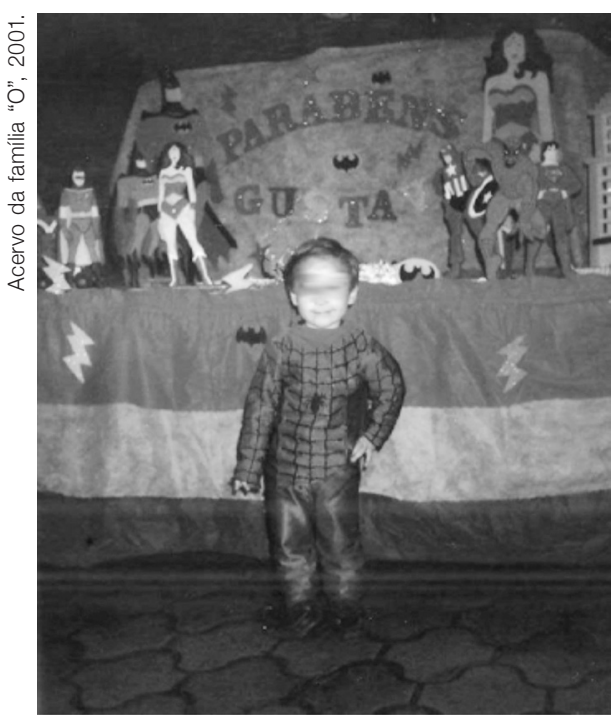

"L" ("Homem-Aranha").
Falando em popularidade, o "Homem-Aranha" é desde a década de 1960 um dos mais populares super-heróis dentre as mais variadas mídias: histórias em quadrinhos, desenhos animados, filmes, jogos etc. A história do Homem-Aranha tem início quando o personagem Peter Parker, órfão criado desde criança pelos tios, já adolescente é picado por uma aranha que provoca mutações no seu organismo. Peter descobre que ao ser picado pela aranha ganhou poderes e passa a utilizá-los para combater o crime em Nova York.

A fotografia foi feita na festa de aniversário de oito anos do primo de "L", em Novo Hamburgo/RS. "L" tinha dois anos e seis meses de idade e, segundo o relato de sua mãe, já adorava o personagem "Homem-Aranha". Ela conta ainda que para fazer a fotografia foi usada uma câmera fotográfica profissional, mas operada por um amador. É possível perceber que o tema da decoração do salão de festas no qual ocorreu o aniversário é de super-heróis, o que fica evidente nos personagens de decoração dispostas sobre a mesa principal. O menino faz pose e sorri em direção à câmera, o que indica que, embora o ambiente estivesse preparado para a festa de seu primo, servia também como pano de fundo para a fotografia dos convidados.

Outra série de grande sucesso entre as crianças é "Harry Potter", a qual teve origem em livros, sendo o primeiro volume publicado em 1997. O sucesso e a crescente popularidade das obras estenderam-se para outras mídias, como filmes e jogos. A história começa com a morte dos pais de Harry Potter por Lord Voldemort, que vive aterrorizando o mundo dos bruxos. Harry fica conhecido nesse mundo como o "menino que sobreviveu", e é identificado com uma cicatriz em forma de raio na testa. Órfão, ele é criado pelos tios (que não são bruxos), mas aos onze anos recebe cartas da Escola de Magia e Bruxaria de Hogwarts. Também aos onze anos é informado pelo guarda-caças de Hogwarts que é um bruxo. Harry vai para a escola de bruxos e lá vive várias aventuras, aprendendo a controlar a magia e a enfrentar Lord Valdemort.

Segundo relato da mãe de "R", a fotografia ao lado foi feita no carnaval do ano de 2010 na instituição educacional da qual

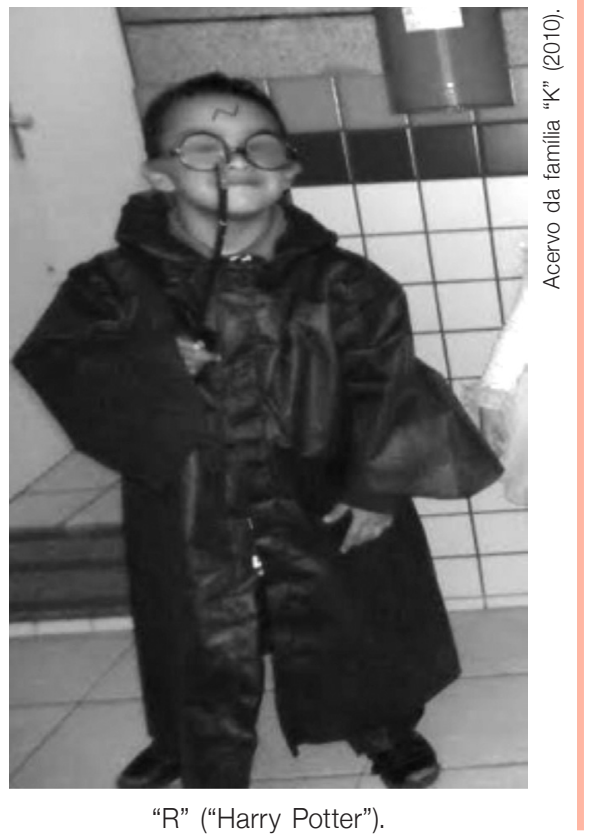

7. Informações disponíveis em: <http://pt.wikipedia. org/wiki/Homem-Aranha>. Acesso em: mar. 2013.

8. Informações disponíveis em: <http://pt.wikipedia. org/wiki/Harry_Potter_ (s\%C3\%A9rie)>. Acesso em: mar. 2013. 
ele é aluno. O menino tinha cinco anos de idade e escolheu a fantasia do personagem Harry Potter por adorar todos os filmes da série. A mãe conta que ele assistiu aos filmes várias vezes e que conhece muito bem os detalhes das histórias. A fantasia foi confeccionada pela avó do menino, que é costureira, e a caracterização foi realizada pela mãe. Percebe-se que não houve escolha de um local específico para fazer a fotografia, isto é, o local não estava decorado com motivos carnavalescos, conforme a época poderia sugerir. Na fotografia, o menino posa empunhando a varinha do personagem e olha, sorrindo, em direção à câmera fotográfica.

Outro super-herói muito popular é "Batman", que teve sua primeira aparição em histórias em quadrinhos em 1932. Desde então, alguns elementos de sua história passaram por mudanças, como roupas, personalidade e parceiros, mas a sede de justiça permanece. Hoje suas narrativas podem ser encontradas em diversas mídias. Os enredos contam as aventuras de Bruce Wayne, empresário e filantropo bilionário que vê seus pais serem assassinados quando ele ainda era criança. Por ter aversão a arma de fogo, aprende várias técnicas de luta e combate, buscando a perfeição física e intelectual. Como não possui poderes sobre-humanos, cria um uniforme inspirado nos morcegos e apetrechos tecnológicos para lutar

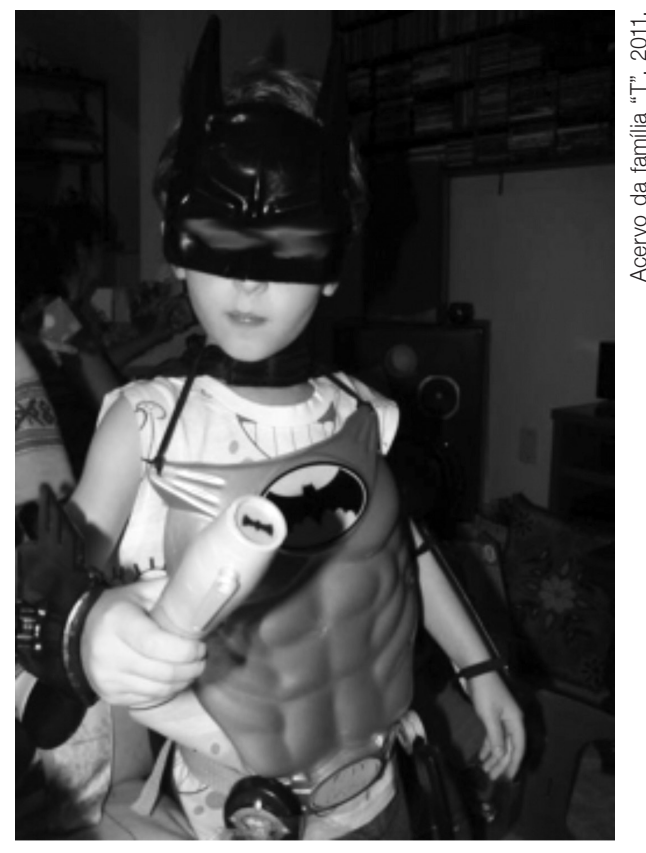

"Z" ("Batman"). contra o crime.

A fotografia de "Z" foi feita em Florianópolis/SC, no ano de 2011, na casa dos tios de "Z". Percebemos que o menino sabe da presença da câmera, mas não faz pose e tampouco há preocupação com a preparação de ambiente, ou fundo para a fotografia. Conforme o relato da tia, "Z", com quatro anos de idade, "ama se vestir de Batman. Sente-se o próprio com todos esses apetrechos, e faz questão de usá-los todos, pronto para salvar Gottam City!”.

"Batgirl"10 surgiu a partir do sucesso da série de TV de Batman exibida na década de 1960. Era uma bibliotecária e auxiliava Batman e Robin na luta contra o crime, mas, após ser baleada pelo vilão Coringa, perde o movimento

9. Informações disponíveis em: <http://pt.wikipedia. org/wiki/Batman>. Acesso em: abr. 2013.

10. Informações disponíveis em: <http://pt. wikipedia.org/wiki/ Batgirl>. Acesso em: abril. 2013. das pernas, adota o nome "Oráculo" e passa a fornecer informações pela Internet aos super-heróis.

A fotografia de "G" e "D" foi feita em Florianópolis/SC, no ano de 2011, na casa dos tios e padrinhos de " $G$ ", onde acontecia um encontro de familiares durante as férias de verão. De acordo com a madrinha e tia do menino, as crianças gostam do Batman e de se vestir de super-heróis. Ela relata ainda que "G", na época com dois anos de idade, sempre usava capa, seja a da fantasia 


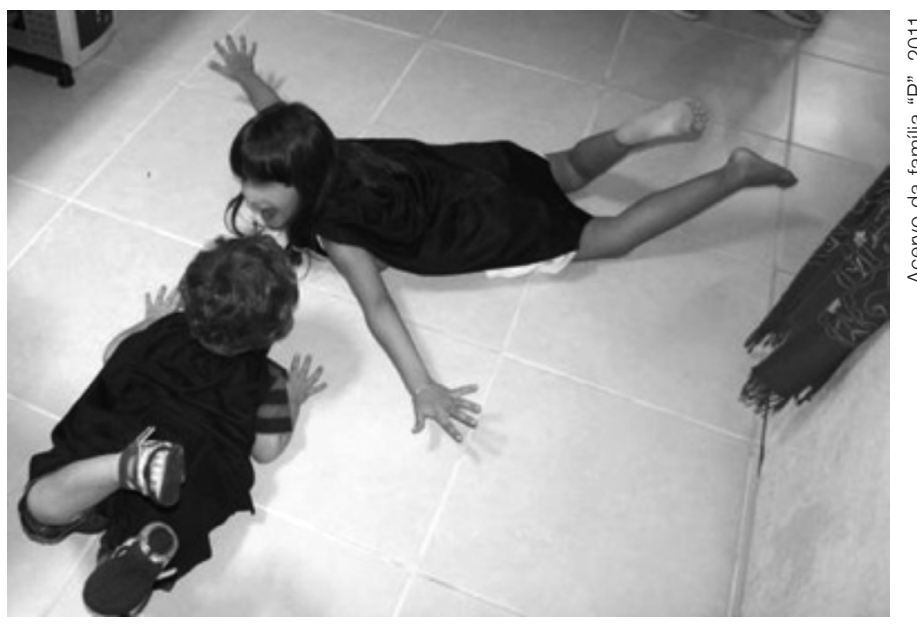

"G" e "D" ("Batman e Batgirl").

ou uma fralda amarrada no pescoço. "D”, com cinco anos de idade, também adorava se vestir de Batman: "Quem a chama de Batgirl são os adultos; para ela isso parece ser irrelevante, o que importa é fantasiar-se e brincar com o irmão e os primos", conta a tia da menina. Nesta fotografia é interessante perceber que não há preocupação com poses ou preparação do ambiente; parece que a intenção foi flagrar um momento espontâneo de brincadeira das crianças, que, naquele instante, estavam "voando", segundo a tia.

Ao utilizar um brinquedo ou uma fantasia, as crianças têm em mãos um aliado na construção de suas narrativas e são justamente essas narrativas que contribuem para uma melhor compreensão das culturas infantis pelo adulto. Ou seja, "[...] o brinquedo não condiciona a ação da criança: ele lhe oferece um suporte determinado, mas que ganhará novos significados através da brincadeira"11.

Por isso, um olhar atento pode contribuir para uma melhor compreensão das relações que as crianças estabelecem com as narrativas e os personagens de filmes, desenhos animados, livros, revistas etc. É a possibilidade de materializar as narrativas que assistem na televisão ou em outras mídias audiovisuais e de interagir de acordo com o sentido que a imagem dos objetos indica ao enredo da brincadeira, fazendo com que as crianças atribuam ainda mais sentido às suas próprias narrativas e aos personagens que assumem. E, brincando, negociam-se regras, constroem-se e reconstroem-se valores, conceitos, enfim, conhecimentos sobre as coisas do mundo.

\section{AS FOTOGRAFIAS, OS PERSONAGENS MIDIÁTICOS E A PRÁTICA PEDAGÓGICA EDUCOMUNICATIVA}

"Educomunicação é essencialmente práxis social."

Ismar Soares

O exercício de analisar as fotografias foi possível graças às informações relatadas pelas pessoas que as disponibilizaram. Assim, nossas análises

11. BROUGÈRE, 2008, p. 9. 
consideraram uma das premissas apresentadas por Mauad ${ }^{12}$ para o tratamento crítico das imagens fotográficas, qual seja o princípio da intertextualidade, isto é, "[...] uma fotografia, para ser interpretada como texto (suporte de relações sociais), demanda o conhecimento de outros textos que a precedem ou que com ela concorrem para a produção da textualidade de uma época”. Em outras palavras, a análise foi possibilitada pela relação de nossas impressões sobre as imagens com os relatos pessoais e pela aproximação às narrativas vividas pelos personagens midiáticos referidos pelas crianças fotografadas.

Como podemos perceber por meio dos relatos, há um grande envolvimento entre as pessoas e as fotografias cedidas, uma relação de afetividade com essas imagens, com as pessoas e os lugares, com um momento vivido, com uma lembrança. Por isso, entendemos que tais relatos podem contribuir para uma melhor interpretação das imagens.

Diante disso, tomados os devidos cuidados no tocante à interpretação das fotografias, reconhecemos que estas podem ser utilizadas como recurso para compreender a realidade vivida pelas crianças contemporâneas fora do contexto escolar e, a partir daí, se pensar em práticas pedagógicas que abarquem as expectativas e necessidades das escolas, das famílias e das crianças que vivem em meio às referências midiáticas.

Os desenhos animados, filmes, histórias em quadrinhos, seriados etc., referidos pelas crianças em suas brincadeiras, costumam possuir narrativas que envolvem a luta do bem contra o mal, efeitos sonoros que conotam suspense e ação, efeitos visuais que deixam os enredos mais atraentes, o que parece fazer com que as crianças se identifiquem com os personagens e as suas histórias; assim, é compreensível que as crianças também queiram se transformar nos personagens e viver suas aventuras.

Uma vez que as mídias possuem recursos capazes de captar a atenção das crianças, as quais se apropriam também de valores, princípios e conceitos ali propagados, ampliar o entendimento do papel desempenhado por essas importantes referências culturais contemporâneas na vida das crianças é uma necessidade, sobretudo, quando a comunidade escolar já não se configura mais como único espaço de formação e de construção e reconstrução de conhecimentos. Pensando nisso, parece-nos pertinente a contribuição da área da Educomunicação no que se refere à inter-relação das áreas da Educação e da Comunicação. A Educomunicação é definida por Soares ${ }^{13}$ como:

[...] conjunto de ações inerentes ao planejamento, implementação e avaliação de processos, programas e produtos destinados a criar e a fortalecer ecossistemas comunicativos em espaços educativos presenciais ou virtuais, assim como a melhorar o coeficiente comunicativo das ações educativas, incluindo as relacionadas ao uso dos recursos de informação no processo de aprendizagem.

Por ecossistema comunicativo, Soares ${ }^{14}$ entende um "ideal de relações,

12. MAUAD, 2004, p. 20

13. SOARES, 2002, p. 24

14. SOARES, 2011, p. 44 construído coletivamente em dado espaço, em decorrência de uma decisão estratégica de favorecer o diálogo social, levando em conta, inclusive, as potencialidades dos meios de comunicação e de suas tecnologias". 
Os conceitos de Educomunicação e de ecossistema comunicativo trazidos por Soares contribuíram para que pensássemos aqui em práticas pedagógicas educomunicativas como possibilidades para a atividade docente realizada nas escolas de hoje. Por práticas pedagógicas educomunicativas estamos entendendo aquelas que consideram as possibilidades comunicativas oferecidas pelas particularidades culturais de nosso tempo, como o papel que jogam mídias e dispositivos de comunicação na construção do sujeito-criança, construindo processos e caminhos diversificados pelos quais crianças e professores atribuam significados às atividades escolares. Nesse sentido, estabelecer ecossistemas comunicativos é viabilizar o dialogo construtivo, a possibilidade de coautorias nas atividades escolares, diferenciando-as daquelas que reduzem os potenciais midiáticos ao seu aspecto instrumental, ilustrativo e, por vezes, de ocupação do tempo. Uma prática pedagógica educomunicativa possibilita a criação coletiva, a circulação dos sentidos e a construção do conhecimento significativo.

\section{CONCLUSÃO}

Com o presente estudo, percebeu-se que o acesso às mídias tem permitido às crianças o contato com diferentes referências culturais, sendo possível perceber, por meio de fotografias de acervos de família, que os personagens de programas de televisão, filmes, desenhos animados, revistas em quadrinhos, livros etc. fazem parte da cultura infantil, participando das suas brincadeiras e, em consequência, da construção e reconstrução de seus conhecimentos e culturas próprios.

Entendemos que as fotografias podem contribuir para a análise dos professores das relações entre as crianças e suas referências culturais. Dessa forma, práticas pedagógicas educomunicativas - porque preocupadas com a ampliação dos índices comunicativos no "que fazer" pedagógico - revelam importantes contribuições no que se refere às novas demandas da escola nesta contemporaneidade marcada pela forte presença das referências midiáticas.

Nesse sentido, fotografias que trazem referencias midiáticas das crianças podem contribuir para o estabelecimento de ecossistemas comunicativos, por favorecerem a compreensão dos professores quanto à participação das referências midiáticas no entendimento de mundo do sujeito-criança e, a partir daí, criarem condições para que ocorra o diálogo com e entre as crianças.

\section{REFERÊNCIAS BIBLIOGRÁFICAS}

BARBOSA, M. C. S. Culturas escolares, culturas de infância e culturas familiares: as socializações e a escolarização no entretecer destas culturas. Revista Educação \& Sociedade, Campinas, v. 28, n. 100. Especial, p. 1059-1083, out. 2007.

BENJAMIN, W. A obra de arte na era da sua reprodutibilidade técnica. In:

Sobre arte, técnica, linguagem e política. Antropos, 1992. 
BROUGÈRE, G. Brinquedo e cultura. 7. ed. São Paulo: Cortez, 2008.

CITELLI, A. Educação e mudanças: novos modos de conhecer. In: (Org.). Outras linguagens na escola: publicidade, cinema e TV, rádio, jogos, informática. 4. ed. São Paulo: Cortez, 2004.

LEITE, M. M. Retratos de família: leitura da fotografia histórica. 3. ed. São Paulo: Editora da Universidade de São Paulo, 2001.

MAUAD, A. M. Fotografia e história: possibilidades de análise. In: CIAVATTA, Maria; ALVES, Nilda. A leitura de imagens na pesquisa social: história, comunicação e educação. São Paulo: Cortez, 2004.

PACHECO, E. D. Televisão, criança e imaginário e educação: dilemas e diálogos. In: SEMINÁRIO NACIONAL DE LITERATURA INFANTIL E JUVENIL. São Paulo, 1999. Disponível em: <http://www.aurora.ufsc.br/artigos/artigos_alfabeto_ TV.htm>. Acesso em: 10/03/2013.

SALGADO, R. G.; PEREIRA, R. M. R.; SOUZA, S. J. e. Pela tela, pela janela: questões teóricas e práticas sobre infância e televisão. Cadernos Cedes, Campinas, vol. 25, n. 65, p. 9-24, jan./abr. 2005.

SOARES, I. O. Educomunicação: o conceito, o profissional, a aplicação; contribuições para a reforma do ensino médio. São Paulo: Paulinas, 2011.

- Gestão comunicativa e educação: caminhos da educomunicação. Revista Comunicação \& Educação. São Paulo, n. 23, jan./abr. 2002. 